\title{
The Politics of Electronic Remembrance. A Brief Study of Deep Media Metaphors - in art and other political lifeforms.
}

\author{
Morten Søndergaard \\ Aalborg University \\ A.C. Meyersvænge 15, 2450 Copenhagen \\ mortenson@hum.aau.dk
}

\begin{abstract}
Deep media is all around us, influencing us in ways we do not even know or discover. How does that effect the way we approach mediated artforms? And how does it effect remembrance of people and things? This paper examines the metaphors of deep media, in art and other practices, and ask if what a politics of electronic remembrance might entail?
\end{abstract}

Deep media. Art practices. Politics. Remembrance.

\section{INTRODUCTION}

"Curating deep media art... is about the politics of ... making cultural forms, processes and practices visible, and visible in a new way". (Bulatov, 2018)

When the Danish electronic composer, Else Marie Pade, was in the last part of her life she did not listen often to the works of electronic music she composed many years before. A different age, a different time, the recollection of the 1950s and 60a was waning and decomposing as her life was moving slowly towards the end. ${ }^{1}$

However, on one occasion that process was halted, for a while at least, as she was asked to listen to her own compositions while partly captive of an old and tired brain.

\footnotetext{
${ }^{1}$ This draws on the sound and video-recordings made by Ane Mette Ruge and Emil Boserup in 2012, four years before the death of the renowned Danish pioneer of electronic music, Else Marie Pade.

In the video you see the composer in her late age, listening to her own composition 'Faust' from 1962. Due to a slowly increasing state of dementia, Else Marie Pade is sliding in and out of 'different states of consciousness', more or less 'provoked' by her own composition and by the conditions of the shared social situation of listening and recording.

The footage, a single-angle mediation, reveal, to a degree, Else Marie Pade sliding in and out of what appears to be a 'meta-space' of a life lived by. This is where I would like to depart on my inquiry today. The question is, what did the recordings capture that afternoon?
}

Ethics is deeply mediated by conventions and culture, and those ethics tells us that when a brain is old and tired we should not publicly expose the person of that brain, nor make it the subject of critical study. The conventional framing of our life is thus that the brain is considered sacred, as the bearer of something unapproachable and 'unmediated'. As if the critique of the human brain as the epicentre of epistemology and knowledge never happened.

Knowledge about things and persons is of course always mediated; or is, rather, never unmediated. Whereas the first proposition presupposes that we are always mediating something or someone, even self-mediating, then the latter points to the occasions where technology takes over from the human... revealing a deeper mediation of electronic remembrance. Thus, whereas the first points towards a general premise and boundary of perception and cultural (conventionalized) knowledge, its mediation, the second proposition is raising the question: what is mediation mediating?

We could also ask: Is there such a thing as electronic remembrance, and what would that then look like?

The situation of Else Marie Pade's listening to her own electronic memories seems to suggest this. But it is not so simple just to state: this is then electronic remembrance. First of all, from listening to the sounds she herself recorded she was not silent, but loudly reflecting on the choices she made and the electronic sounds or edits that are not there. Those she chose not to use. 
In this sense, and as a first observation, electronic memory is not about memory at all, but about remembrance. It is not about WHAT is recorded, but WHAT was not recorded. It is about something outside language, and outside 'meaning' even. As George Bataille has it, "There is no pure and simple communication; what is communicated has a direction [sens] and a color" (Bataille, 1982, 315); the ambiguity is not that there is no meaning, but knowing that we are knowing nothing. A discourse full of meaning steals the life of which it speaks, according to Bataille, and thus 'writing' also 'exscribes' meaning, writing it elsewhere, outside the text (or here: the electronic tape recorder, by inference), in a place where human memory is not the source nor the recipient, but something else, as further developed by Jean-Luc Nancy:

... this "outside" - entirely exscribed into the text - is the infinite retreat of meaning by which each existence exists. Not the brute datum, material, concrete, reputed to be outside meaning and which meaning represents but the "empty freedom" through which the living being comes to presence - and absence. This freedom is not empty in the sense of being vain. No doubt it is not directed toward a project, a meaning or a work. But it uses the work of meaning to expose, to lay bare the unusable, unexploitable, unintelligible and unfoundable being of being-in-the-world. That there is being, or some being or even beings, and in particular that there is us, our community (of writing-reading): that is what instigates all possible meanings, that is what is the very place of meaning, but which has no meaning. (Jean-Luc Nancy, 1979)

The first deep media metaphor is thus pointing towards the issue of 'electronic remembrance', which could be described as the exscription of knowledge and meaning, writing it elsewhere 'outside' the human brain, humans, as well as outside electronic storage media - inspired by Bataille and Jean-Luc Nancy, I understand 'outside' as that which is mediating the mediated, framed by a technological transcendence, but not restricted by an 'essence' of cultural signification.

There is a tension between mediation and remembrance, staging a range of thresholds, and it is here I am arguing that the metaphors of deep media operate, oscillating in-between knowing and knowing nothing, signifying and escribing meaning.

Else Marie Pade's 'deep mediation' of her own composition is a threshold practice border lining symbolic representations and cultural forms of deep media, and thus operating without clear or conventional metaphors to guide them. They are on the 'threshold' of cultural representation, in effect representing nothing (that we can know or has meaning).

\section{NONHUMAN THRESHOLDS}

Practice seems to be crucial to deep media (that mediate the mediated by unknowing it). Especially the status of scientific and artistic practice should be addressed. How may art mediate what science aim to mediate through practice? How might art operate as deep media?

Not in pursuit of definite answers, but rather in pursuit of the right framework to investigate these questions, between 1996 and 2007, the Danish media artist Thorbjørn Lausten develops and refines a 'data practice' - artistic methods of researching 'reality-constructs' from 'outside' the human scale and cognitive horizon.

His artistic exploration is conducted as a series or system of optical re-membranes. It is an ongoing investigation of ways of mediating scientific data (primarily understood as measurements from the sun, meteorological phenomena, magnetism etc.) by performing them in real-time in visual (and auditory) 'practice fields.'

As such, they are attempts to move beyond mediaspecificity and questions about mediation that is framing art, and instead frame the question inside an artistic practice, as a deep mediation of that question: "Today, as artists, we have to put the investigation and consciousness of media behind us," Lausten claims. "Instead, we should move on, and use the experience from the investigations in our practice as a part of, and frame for, our practice." (Lausten in: Søndergaard and Weibel 2008)

In the project SOL (2004) he is making this point very visible, as it were. Focusing on real time data streams from different measurements of the sun (e.g. the magnetic field and sun spot-activity) SUN as artistic practice reveal that we are never really able to represent the non-human world of the sun. It is operating in-between technological-driven categorizations and the non-human perspective of life without categories - where the technological mediation and categories are 'interpretations' based on deep trajectories, afterimages, at best. It is only 'knowledge' (in the vein of Haraway) when situated in the moment of the real-time interaction of data, which is being mediated to us on the projection screen.

Similarly, in MAGNET (2007), where the focus is on meteorological data and the weather as medium, artistic practice in Lausten's conception affords a field of visual systems that reflects upon the cultural status of art as post-human practice. 
In 'Opera Aperta', Umberto Eco argues that aesthetics and art should be approached as 'a structure; a system of relations.' (Eco, 1962) and Thorbjørn Lausten clearly investigates the problem of representation of reality in art as a system of relations to the nonhuman world. According to Lausten, it is absolutely essential that the relationship of art and 'reality' remains un(re)solved. He operates in or at the thresholds of representation and knowledge, without ever reaching a point of cognitive clarity.

Thorbjørn Lausten's modality is an investigation of the electronic afterimages of the 'presence' of the nonhuman world, and bring it to our attention, as he explicitly does not wish to "exist inside the problem of representation' (Lausten in: Søndergaard and Weibel, 2008). Instead, his investigations become discursive turning points in systems of thresholds. We do not see reality itself - but we may glimpse thresholds in the streams of data rushing towards us.

Peter Weibel claims that the historic competition between image and concept, as a division of labour between art (concrete pictures) and science (abstract numbers), is changing - producing a threshold and a new period of art, even:

"Now we are on the threshold of a new period where the strict division is becoming obscure and obsolete. Thorbjørn Lausten is one of the few artists advanced enough to be aware of this threshold." (Søndergaard and Weibel, 2007, 11)

There is an argument to be made that this threshold is not between an old and a new period (it is not a linear change), but rather pointing towards a more fundamental game of representation which conditions any artistic practice: the game played between the cognitive and perceptive limitations of the human and the nonhuman world completely remote from any human sensing or interpretation.

In SOL and MAGNET, the threshold is almost visible, artistic practice creates deep media systems affording afterimages of electronic activities: The non-human world is always deeply mediated in the world surrounding us, but we are mostly unaware of that world and of the entanglement of deep media systems, and of what it is mediating... a world beyond the human perceptual and conceptual grasp.

In this way, it is possible to see Thorbjørn Lausten's data-screens and projections as remembranes operating on the threshold of human and nonhuman worlds.

\section{A (BIO)POLITICS OF ELECTRONIC REMEMBRANCE?}

Else Marie Pade and Thorbjørn Lausten approaches the threshold from two sides of the remembrane, demonstrating its non-subjective and non-dualistic structure: There is a tension between Internal and external, non-subjective and nonobjective 'forces'.

As I am not offering any fixed definition of 'deep media', or the 'post-human' condition here, but I am pointing out some trajectories using metaphors as situated players (or what Haraway calls the language-mediated actors, see below) of the language-game we play when we are operating with the 'hidden ambiguities' of conventional science, which, as Donna Haraway points out:

"... is rhetoric, a series of efforts to persuade relevant social actors that one's manufactured knowledge is a route to a desired form of very objective power. Such persuasions must take account of the structure of facts and artifacts, as well as of language-mediated actors in the knowledge game. Here, artifacts and facts are parts of the powerful art of rhetoric. Practice is persuasion, and the focus is very much on practice.". (Haraway, 14)

Notice that practice is also ambiguous, since it is operating rhetorical 'pursuasion' which hides the thresholds of the process of exscription. The Else Marie Pade example shows that there are patterns of reality which are not covered by scientific knowledge, we have more limits - as scientists and as humans - than we have knowledge.

What we need is to be able to operate with and in those limits, as thresholds through which we may, occasionally, inscribe new signification and identify new cultural forms. Electronic remembrance is a visual metaphor, which, as Haraway points out, goes beyond fixed appearances (and conventional readings). These metaphors operate in-between the real world and production of scientific knowledge, as visual language mediators of situated knowledge:

"...the visual metaphor allows one to go beyond fixed appearances, which are only the end products. The metaphor invites us to investigate the varied apparatuses of visual production, in-cluding the prosthetic technologies interfaced with our biological eyes and brains. And here we find highly particular machineries for processing regions of the electromagnetic spectrum into our pictures of the world. It is in the intricacies of these visualization technologies in which we are embedded that we will find metaphors and means for understanding and intervening in the 
patterns of objectification in the world - that is, the patterns of reality for which we must be accountable. In these metaphors, we find means for appreciating simultaneously both the concrete, "real" aspect and the aspect of semiosis and production in what we call scientific knowledge." (Haraway, 16)

Else Marie Pade's listening and electronic remembrance (set apart from the setting that she is staged in by the artists documenting her and asking her to listen to her own practice) cannot be characterized as 'practice', and is for this reason not playing with the conventional game of language-mediation (to stay with Haraway's term).

We may ask, what is 'real' in that situation? It stays 'outside' even ethical considerations, since what emerges are not objectifications or behaviourpatterns but a re-writing of memories elsewhere, on a screen of remembrance. As such, it would be possible to see the recollection through listening as a situated re-membrane, upon which are projected that which was never stored or recorded. That which is not 'ontologically' present in a dualistic sense but is hiding behind the choices that removed it from the ontological theatre and which reveal themselves in the moment Else Marie Pade comments her own work while listening to it becoming their situated remembrane.

She is not 'the sick' and the spectators are not 'the healthy', the technological mediation mediates a challenge, freeing the tape-as-medium from any false metaphors of the brain being the centre of knowledge.

The threshold is where we address it as a remembrane, a collector and a selector of choices and inscriptions elsewhere. Unknowing is not knowing nothing but knowing that you are knowing nothing. The re-membrane operates in-between exscribed human memory and the technology which makes it possible to mediate it as remembrance of things and actions lost. In this way, it appears as if the real is a collection of such things and actions lost. And the threshold to where those lost things and actions may appear to us, again, are framed by a situated metaphorical questioning.

\section{FINAL REMARKS}

In what way does this formulate a politics of electronic remembrance? Bruno Latour (1998) claims that material objects and things are politically charged. (Latour, ref). In the same vein, Peter-Paul Verbeek states, that "[w]hen politics is no longer just a question of people, but also of things, it indeed has tremendous consequences for our democracy. After all, the political role of material objects is not the product of democratic decision-making... The recognition that things are politically charged is therefore also a serious challenge for politics." (Verbeek, 2010)

Electronic remembrance feed into the (philosophical and real) 'problem' of establishing the relationship of people (ie their (re)actions) and things (and their materiality). This 'problem' becomes a problem exactly because the 'duality view' of people/things suggests that only what is 'here', as phenomenon or object, is part of politics and whether it reserves people or things, decisionmaking or objects, as the main operator, it leaves a mark, a history, a record. This paper suggests that electronic remembrance changes all that... it points towards the unmarked, ahistorical, unrecorded matters as political trajectories, precisely because they have an effect on people and things, even if there are no traces of them.

\section{REFERENCES}

Bataille, G. (1945) Sur Nietszche. Volonté de chance. Collection Blanche, Gallimard, Paris.

Bulatov, D. (2018) The New State of the Living: Deep media, Url (retrieved 11 August, 2019): https://webcache.googleusercontent.com/search ?q=cache:QRclKTJ SA4J:https://permm.ru/wpcontent/uploads/2018/11/RASPISANIEKONFERENTSIl timetable engl-1.doc+\&cd= $16 \& \mathrm{hl}=\mathrm{da} \& \mathrm{ct}=\mathrm{clnk} \& \mathrm{gl}=\mathrm{dk} \& \mathrm{client}=$ safari

Eco, U. (1989) "The Open Work", MIT Press, Cambridge, Massachusetts.

Haraway D. (1988) Situated Knowledges: The Science Question in Feminism and the Privilege of Partial Perspective. Feminist Studies, Vol. 14, No. 3, 575-599.

Latour, B. (1993) We Have Never Been Modern. Harvard University Press, Cambridge, Massachusetts

Nancy, J.L. (1979) Exscription. Yale French Studies, No. 78, 47-65.

Søndergaard, M. and Weibel, P. (2008) MAGNET: Thorbjørn Lausten - Visual Systems. Kehrer Verlag, Heidelberg, Germany.

Verbeek, P-P. (2012) On Art and the Democratization of Things. Politics at Issue. Url (accessed $11 \quad$ August 2019) https://onlineopen.org/on-art-and-thedemocratization-of-things 